\title{
The Effect of Reading Short Drama on the Development of Vocabulary Skill of Iranian Advanced EFL Learners of English
}

\author{
Mostafa Dayyani Kheirabadi (M.A.) \\ Dept. of English, Tarbiat Modares University, Tehran, Iran \\ Tel: 98-912-154-8251_E-mail: dayyani.mostafa@yahoo.com
}

Vahid Fallah Golchin (M.A.) (Corresponding author)

Dept. of English, Science and Research Branch, Islamic Azad University, Tehran, Iran

Tel: 98-912-546-8612Ｅ-mail: vahid.fallah11@yahoo.com

Received: April 15, 2013 Accepted: May 4, 2013 Published: May 5, 2013

doi:10.5296/ijele.v1i3.3640 URL: http://dx.doi.org/10.5296/ijele.v1i3.3640

\begin{abstract}
The prominent role of reading in language learning, particularly at upper-intermediate and advanced levels, is beyond doubt. At these levels, the text plays a primary role in developing language learners' reading skill in particular, and their proficiency level in general. This study was carried out to find the effectiveness of reading drama on the development of advanced EFL learners' vocabulary skill. The participants of the study were 40 (all females) advanced EFL learners. The participants were randomly assigned to two groups (each consisting of 20 students): one group for reading drama (the experimental group), and one group for traditional reading (the control group). During the treatment period the experimental group received short dramas while the control group received reading instructions through traditional methods. The scores were entered into SPSS software for analysis. The results clearly demonstrated the contribution of reading drama to the development of vocabulary of Iranian advanced EFL learners of English.
\end{abstract}

Keywords: reading drama, traditional reading, vocabulary 


\section{Introduction}

It is highly repetitive to say that the aim of art is to 'instruct by pleasing' (Kelsall, 1985). Nonetheless the use of literature as a means of instruction has always provoked controversies over the logic and wisdom of the issue. Arthur (1968, in Moradan, 2006) draws attention to the versatility of literature as an additional source of teaching structure, vocabulary, and culture. Literature is a mixture of entertainment and instruction. It deals with topics and experiences common to all humans. Students genuinely interested in reading works of literature will be emotionally and intellectually involved. Literature is regarded as a kind of escape. In the hustle and bustle of modern life, literature is a haven of tranquility which helps the reader to lose his consciousness and awareness and enter an elevated imaginary world. These are some advantages of reading literature which are beyond the language itself (Moradan, 2006).

Apart from these benefits, literature has some linguistic and pedagogical advantages. Povey (1972, p. 187, in Brumfit \& Carter, 1986, p. 191) argues that "literature will increase all language skills [on both usage level and use level] because literature will extend linguistic knowledge by giving evidence of extensive and subtle vocabulary, usage, and complex and exact syntax". Literature, drama in particular, presents language in discourse in which the sociolinguistic and discourse aspects of language receive attention. Therefore, literature is a primary source for developing an awareness of language use (McKay, 1986).

There are other advantages of literature which McKay (1986) has been keen to emphasize. The first one is that literature can yield an improvement in reading proficiency and development of interpretative skills. In order to have a better understanding of reading proficiency, it is essential to understand what is involved in the reading process. Widdowson (1974, p. 74, in Brumfit \& Carter, 1986, p. 192) regards reading "not as a reaction to a text but as interaction between writer and reader mediated through the text". For some learners, the affective, attitudinal, and experiential factors of literature will generate motivation. McKay (1986) argues that improvement in reading proficiency, which is a direct result of interacting with literary texts, will contribute to a student's academic and occupational objectives. From a sociocultural perspective, Marshall (1979, in Brumfit \& Carter, 1986) and Frye (1964, in Brumfit \& Carter, 1986) share this opinion that by reading literature and constant exposure to it both teachers and students can show remarkable tolerance for cultural differences.

With regard to the aforementioned points, the following research question was raised:

Does reading drama contribute significantly to the development of vocabulary skill of Iranian advanced EFL learners of English?

\section{Review of the Related Literature}

\subsection{The Role of Literature in English Language Teaching: A Historical Perspective}

During the last quarter of the century, language teaching has witnessed an array of methods, the so-called 'designer methods of the 1970s' (Brown 2000, p.103), which aim at developing 
the communicative abilities of the learners. In this communicative era the role of literature, once the core material for language teaching, has been widely ignored. In fact literature has become an intimidating term and many teachers feel that it is too difficult for ESL students (Gajdusek, 1988). The sad truth is that this communicative era has not impacted on all communities in the same fashion. There are still millions of English learners all over the globe who struggle to learn communication so as not to communicate. Many methodologists have lost sight of the fact that the overwhelming majority of language learners are EFL ones who might never have the chance to speak to an English native speaker. In these EFL settings it is the text or the material which should shoulder the double burden of motivation and engagement. If the text does not provide the learners with interest and insight (Robinson, 2002), then language learning will be analogous to an exacting aimless exercise. Depriving a language of its culture and literature will eventuate in the trivialization of that language. Literature and culture are bursting with tensions and controversies, therefore overlooking this fact will end in nothing but some trivial facts and figures.

\subsection{Advantages and Disadvantages of Using Literature}

Although there is no doubt about the invaluable authenticity attached to literary texts (Collie \& Slater, 1987, in MacKay, 2001), there are still some reservations about how and to what extent literature should be employed in language teaching. Different researchers have looked upon literature from different angles.

According to McKay (2001), using literature as content has three major advantages:

1. It represents the significance of authors' choice of form to achieve communicative goals.

2. It is a very good source for the integration of all skills.

3. It raises cross-cultural awareness/consciousness.

Ur (1996) has focused on both the advantages and disadvantages of literature teaching ( $p$. 201):

"Advantages of literature teaching:

1. Literature can be very enjoyable to read.

2. It provides examples of different styles of writing, and representations of various authentic uses of the language.

3. It is a good basis for vocabulary expansion.

4. It fosters reading skills.

5. It can supply an excellent jump-off point for discussion or writing.

6. It involves emotion as well as intellect, which adds to motivation and may contribute to personal development.

7. It is a part of the target culture and has value as part of the learners' general 
education.

8. It encourages emphatic, critical and creative thinking.

9. It contributes to world knowledge.

10. It raises awareness of different human situations and conflicts."

"Disadvantages of, or problems with literature teaching:

1. Much literature is written in language that may be difficult for foreign language learner to read.

2. We can use simplified versions, but these are a poor representation of the original.

3. Many literary texts are long and time-consuming to teach.

4. The target-language culture on which the literature is based is alien to learners and may be difficult for them to relate to.

5. By using texts as a basis for language teaching we may spoil learners' enjoyment and appreciation of them as literature.

6. Students of science and technology may find literature irrelevant to their needs."

Oster (1989) reminds this fact that discussing literature can promote academic skills, reduces the threat and encourages risk-taking in both written skills. "Literature engages the emotions and encourages personal identification" (p.88). Rosenblatt (1976, in Oster, 1989) relates literature to a 'medium of exploration'. Another benefit of reading and discussing literature which is unanimously agreed upon by some researchers (McKay, 1982; Oster, 1989) is the stimulation of creativity in learners. The root cause of this creativity can be sought in still another byproduct of literature which should not be neglected: imagination. Imagination is a basic distinguishing feature of literature (Obeidat, 1997).

\subsection{Potential Applications of Literary Texts in the Classroom}

Literature plays a pivotal role in the classroom, it encourages speaking (Enright \& McCloskey, 1985, in Gajdusek, 1988) and problem solving; it poses meaningful "referential questions" (Brock, 1986, in Gajdusek, 1988); it genders interactive small-group work (Long \& Porter, 1985, in Gajdusek, 1988); and it develops critical thinking skills (Newman, 1996).

In addition, literature offers a depth to language learning (Stern, 1991). Stevick (1976, in Stern, 1991) and Newton (1985, in Stern, 1991) refer to this feature as the dimension of depth' of the language. They believe that literature involves learners mentally and leads to a kind of communication which is more than superficial. In discussion of literary texts, there is no 'one right answer' (Gajdusek, 1988) thus learners can voice their opinions with no fear and anxiety. It accounts for the fact that the process is of paramount importance.

According to Stern (1991) literature offers its benefits to EFL/ESL learners in different ways: linguistically, culturally, and aesthetically. Beyond these advantages which literature offers, it promotes "cognitive and aesthetic maturation" (Gregg \& Pacheco, 1981, in Stern, 1991, p. 


\section{Macrothink}

329), enables the learners "to make critical and mature judgments" (Hargreaves, 1969, in Stern, 1991, p. 329), creates "a feeling and appreciation for the language" (Shumaker, 1975, in Stern, 1991, p. 329), and has the potential "to move the reader" (Slager \& Marckwardt, 1975, in Stern, 1991, p. 329).

\subsubsection{Contributions of Drama to Language Proficiency}

"Drama is like the naughty child who climbs the high walls and ignores

the 'No Trespassing' sign. It does not allow us to define our territory so exclusively: it forces us to take as our starting-point life not language" (Maley \& Duff, 1982, p. 15, in Heath, 1993, p. 191).

Recently, during 1980s and 1990s, there has been a shift of focus from drama which is oriented to production and performance to drama which 'places the focus on understanding and exploiting the true nature of the art form' (Byram 2000, pp. 186-187). This shift of focus is thought to have potential for the foreign language classroom.

The value of using drama has been highlighted by researchers such as Maley and Duff (1978, in Robinson, 2002) and Wessels (1987, in Robinson, 2002). Wessels (1987, in Robinson, 2002) believes that drama has a facilitative role for both the teacher and the students to get a grip on reality and it does so in different ways. It can crush the learners' resistance to learning the new language:

- by adding joy to the experience of language learning

- by setting realistic goals for the learners to achieve

- by touching the real experience

- by relating the learning experience to the learner's own experience of life.

And drama can bring about a need in students to learn the language:

- through the use of "creative tension"

- through attributing more responsibility to the learners (Wessels, 1987, in Robinson, 2002).

In this study, three short contemporary drama texts were used to meet the requirements of the research for some practical reasons: Firstly, the students had only ten sessions of treatment, and reading, comprehending, and discussing a long drama, for inexperienced readers, could take the entire ten sessions. Therefore, focusing on short drama texts gave students this chance to experience different writing styles by different dramatist/playwrights. Secondly, contemporary drama texts written in the twentieth century are closer to the language written and spoken in the outside world. Hence, students can comprehend, relate to, identify with, and respond to the texts naturally and pragmatically. 


\section{Method}

\subsection{Participants}

The participants of the study were 40 (all females) advanced EFL learners at Zabansara institute in Tehran. The criterion for choosing them was based on a TOEFL Test administered to those who had passed the upper-intermediate level successfully. The learners were required to get at least 70 percent of the total score. The selection was also premised on the assumption that the participants should not have any experience in reading drama. The participants were between the ages of 22 and 29 years old. They were studying English as a foreign language and had been studying English at the same Institute for about two and a half years. The participants were randomly assigned to two groups (each group consisting of 20 students): one group for reading drama (the experimental group), and one group for traditional reading (the control group).

\subsection{Instruments}

Before the beginning of the treatment, it was essential to make sure that the participants of the study were homogeneous in their proficiency level. To accomplish the purposes of the present study three measuring research instruments were used: 1. Homogeneity test (TOEFL Test), this test was comprised of structure, error recognition, and reading comprehension. The researcher ensured its reliability through pilot-testing done with a group of 30 . The reliability index was 0.76 . 2. A vocabulary test was administered as a pre-test. 3 . The same vocabulary test was administered as a post-test to determine their lexical ability changes, if any.

\subsection{Procedure}

The 40 participants were randomly divided into two groups of twenty. There were no intact classes. First, the homogeneity test (TOEFL Test) was administered to check the participants' proficiency level. Then the pretest (vocabulary test) was given to the participants of both groups. After that, the treatment began. Reading drama was the focus of one group (the experimental group), and traditional reading was the focus of the other group (the control group). As already mentioned, short contemporary drama texts were used in this study. To achieve the purpose of the study, three dramas were selected. The approach to drama in this study, in Robinson's (2002) terms, was the "b" type experiential approach to drama in which 'language is seen as a tool, not as an object'. It is necessary to underscore this fact that the "a" type analytical approach to drama was beyond the scope of this research. The drama texts were not given to students in advance. They were read in class and then were discussed. The new words and new structures were also highlighted. Finally, participants of both groups received the aforementioned vocabulary test as a post-test. Each group had ten sessions of instruction over a ten-week period. The participants attended a ninety-minute session.

\section{Results and Discussion}

\subsection{Data Analysis}

As mentioned before, the purpose of this study was to investigate the possible contribution of reading drama to the development of vocabulary of Iranian advanced EFL learners of 
English.

After gathering the data, the SPSS software was used for analyzing the data. To achieve the purpose of the study, it was crucial to make sure that the data were normally distributed, i.e. they did not contradict the assumptions of normal distribution. Therefore, Paired Sample t-test which is based on the assumption of normality of data was used for each variable.

One-Sample Kolmogorov-Smirnov Test at the .05 level of significance was used for the data of the two groups and the results are summarized in the following tables. Convention suggests this level be set at .05 where there are 5 chances in 100 of being wrong and 95 chances in 100 of being right. In other words, if there are fewer than 5 chances in $100(0.05$ probability level or level of significance or $\mathrm{p}$ level/value), applied linguists tend to reject the null hypothesis (i.e. $\mathrm{p} \leq$ 0.05) (Hatch \& Lazaraton, 1995).

In this study, if the level of significance is not lower than .05 ( $\mathrm{p} \geq 0.05$ ), then we can conclude that the data are normal, i.e. the data (the scores) are normally distributed.

Table 1. One-Sample Kolmogorov-Smirnov Test for reading drama group

\begin{tabular}{|c|c|c|c|}
\hline & & vp30 & v30 \\
\hline \multicolumn{2}{|l|}{$\mathrm{N}$} & 20 & 20 \\
\hline \multirow[t]{2}{*}{$\begin{array}{l}\text { Normal } \\
\text { Parameters }(\mathrm{a}, \mathrm{b}) \\
\end{array}$} & Mean & 12.30 & 14.75 \\
\hline & Std. Deviation & 2.71 & 3.73 \\
\hline \multirow[t]{3}{*}{$\begin{array}{l}\text { Most Extreme } \\
\text { Differences }\end{array}$} & Absolute & .19 & .21 \\
\hline & Positive & .19 & .21 \\
\hline & Negative & -.16 & -.17 \\
\hline \multicolumn{2}{|c|}{ Kolmogorov-Smirnov Z } & .86 & .98 \\
\hline \multicolumn{2}{|c|}{ Asymp. Sig. (2-tailed) } & .43 & .29 \\
\hline
\end{tabular}

$\mathrm{vp} 30=30$ items of vocabulary (pretest)

$\mathrm{v} 30=30$ items of vocabulary (posttest)

This table indicates that $p$-values for both variables are above 0.05 ( $p \geq 0.05)$, and it is indicative of this fact that the data in this group are normal, i.e. the data (the scores) are normally distributed. For instance, the variable v30 (post-test for vocabulary) is 0.98 ( $\mathrm{p} \geq$ 0.05) in One-Sample Komogorov-Smirnov Test and is higher than 0.05. Therefore, the value of this variable, set at .05 , is normal. 
Table 2. One-Sample Kolmogorov-Smirnov Test for traditional reading group

\begin{tabular}{|l|l|l|l|}
\hline \multicolumn{2}{|l|}{} & $\mathrm{vp30}$ & $\mathrm{v} 30$ \\
\hline $\mathrm{N}$ & 20 & 20 \\
\hline \multirow{2}{*}{$\begin{array}{l}\text { Normal } \\
\text { Parameters(a,b) }\end{array}$} & Mean & 10.70 & 12.20 \\
\cline { 2 - 4 } $\begin{array}{l}\text { Most Extreme } \\
\text { Differences }\end{array}$ & Std. Deviation & 1.30 & 3.44 \\
\cline { 2 - 4 } & Absolute & .19 & .20 \\
\cline { 2 - 4 } & Positive & .10 & .20 \\
\hline Kolmogative & -.19 & -.11 \\
\hline \multicolumn{2}{|l|}{ Asymp. Sig. (2-tailed) } & .85 & .93 \\
\hline
\end{tabular}

According to Table 2., p-values for pretest and post-test of traditional reading group (the control group) are above $0.05(\mathrm{p} \geq 0.05)$, so one can conclude that the data in this group are normally distributed.

Paired Sample t-test is used to estimate the degree of difference (level of significance) between pre-test and post-test for every variable in each group. Therefore, the significance of the Paired Sample t-test for any of the variables leads to this conclusion that treatment has made a positive or negative impact on that particular variable. The tests are set at 0.05 level of significance, i.e. if and when $p$-value is lower than $0.05(\mathrm{p} \leq 0.05)$, the difference is significant (Hatch \& Lazaraton, 1995). It is important to restate this fact that the participants' performances before and after the treatment (pre-test and post-test) are compared and the Paired Sample t-test has been appropriately used for this purpose.

Based on the Table 3, the test for this variable, regarding the $p$-value, is significant $(p \leq 0.05)$.

Table 3. Paired Samples t-test for vocabulary (group1: reading drama)

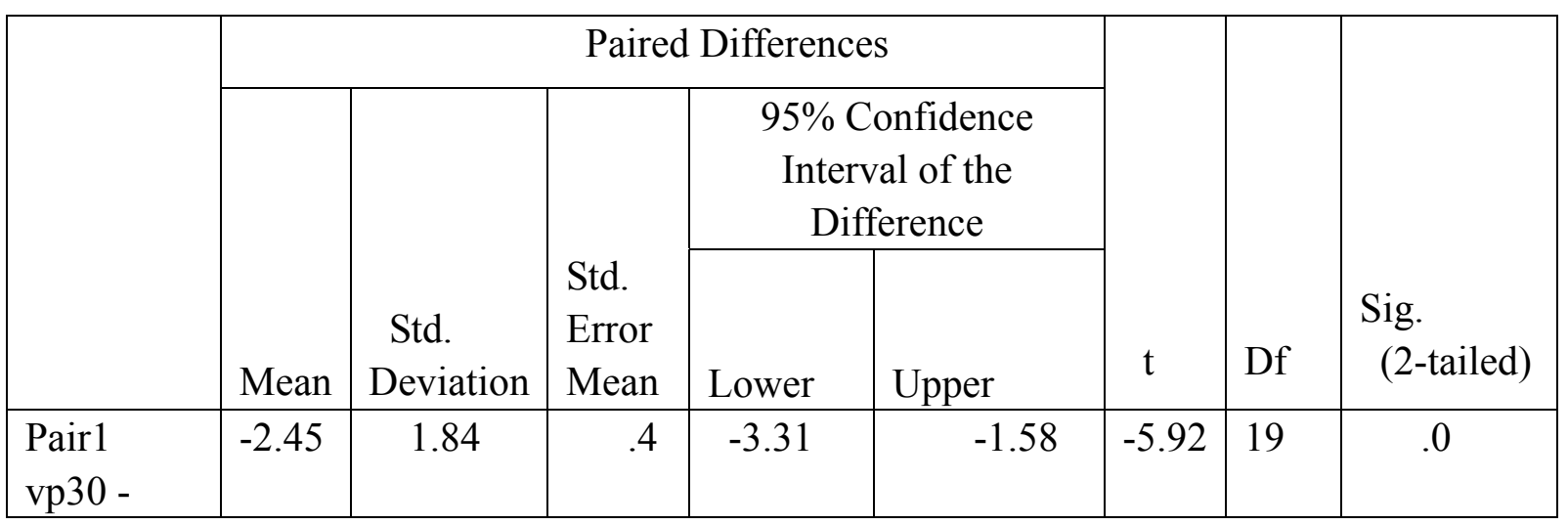

The difference between the means of the pretest (12.30) and the posttest (14.75) for vocabulary in this group is significant $(\mathrm{p} \leq 0.05)$. Treatment has had a positive impact on the performance of the students in the vocabulary test, so the null hypothesis of the study is 
rejected.

According to the Table 4., the Paired Sample t-test shows that the difference between pre-test and post-test for vocabulary is not significant ( $\mathrm{p} \geq 0.05$ ).

Table 4. Paired Samples t-test for vocabulary (group 2: traditional reading/control group)

\begin{tabular}{|c|c|c|c|c|c|c|c|c|}
\hline & & & Paire & Differer & & & & \\
\hline & & Std. & Std. & $\begin{array}{r}95 \% \\
\text { Int } \\
\mathrm{D}\end{array}$ & $\begin{array}{l}\text { onfidence } \\
\text { al of the } \\
\text { erence }\end{array}$ & & & \\
\hline & Mean & & Mean & Lower & Upper & $\mathrm{t}$ & Df & (2-tailed) \\
\hline $\begin{array}{l}\text { Pair1 } \\
\text { vp30 - }\end{array}$ & -1.50 & 3.84 & .8 & -3.29 & .2 & -1.74 & 19 & .0 \\
\hline
\end{tabular}

There is no significant difference between the means of the pretest (10.70) and the posttest (12.20) in the vocabulary section of the test.

To sum up, group 1 (Reading Drama) differed from group 2 (Traditional Reading) significantly with regard to the development of vocabulary (i.e., $\mathrm{p} \leq 0.05$ ), i.e. group 1 (Reading Drama) did better on the tests.

\subsection{Discussion}

With regard to comparisons between groups in the participants' vocabulary scores, the results of this study revealed significant differences in the performance of the participants in the first group (Reading Drama) compared to that of the participants in the second group (Traditional Reading / Control Group). The participants in the first group gained better scores.

HO: Reading drama does not contribute significantly to the development of vocabulary skill of Iranian advanced EFL learners of English.

Result: There was a significant difference between reading drama and development of vocabulary.

As the analyses showed, participants in the first group (Reading Drama) made significant progress in their posttest with respect to vocabulary. Therefore, the treatment had a positive impact on the performance of this group. This finding is in line with what Ur (1996) hypothesized regarding vocabulary. He emphasized that literature is a good basis for vocabulary expansion.

Spack (1985, in Brumfit \& Carter, 1986) also draws the attention to this aspect of literature in which pre-reading vocabulary is done and new words are repetitively used, thus leading to 
growth in vocabulary. Long before Povey (1972, in Brumfit \& Carter, 1986) had made a similar claim which supports this finding regarding vocabulary. He maintained that literature gives extensive and subtle vocabulary.

The positive effects of using literary texts of different genres on language skills have been submitted to critical scrutiny and realized in language classrooms not only in ESL settings but also in EFL settings (Salih, 1986, in Obeidat, 1997). Salih (1986, in Obeidat, 1997) argues that studying literature in English leads to the development of all language skills because all language skills are practiced and exercised in literature courses. Obeidat (1997) maintains that literature exposes the learner to a "considerably wide variety of syntax and vocabulary" and it offers the "language used at its best" to the student.

This finding supports the claim made by many other researchers regarding the positive effects of literature on language proficiency (e.g. Brumfit, 1986; McKay, 1986; Ur, 1996). Povey (1972, in Brumfit \& Carter, 1986) hypothesized that literature increases all language skills on both usage level and use level. Brumfit (1986) claimed that literature is a rich and widely-appealing source of material for reading. McKay (1986) is of the opinion that literature can yield an improvement in reading proficiency and development of interpretative skills. According to Ur (1996), literature 'fosters reading skills'. Duff and Maley (1990, in Byram, 2000, p. 376), in their advocacy of using literary texts as teaching resources assert that literary texts can be used for stimulating language activities. Practical situations by themselves are not always motivating and cannot engage students interactively with the text, with their classmates, and with the teacher in the performance of tasks. The participants in this study also derived great satisfaction from reading drama texts both because of its novelty and its inherent and unique characteristics. Byram (2000) concludes that learners require intriguing topics to read, write, and talk about and literary texts lend themselves to properly being used to meet these needs. Literary texts can be adapted and applied for different levels of proficiency. However, there is a tacit consensus among researchers that literary texts lend themselves to developing a variety of tasks for predominantly intermediate through advanced learners (Carter \& long, 1991; Collie \& Slater, 1987, 1994; Collie \& Porter Ladousse, 1996; Duff \& Maley, 1989, 1990; Lach-Newinsky \& Seletzky, 1990; lazar, 1993; McRae \& Boardman, 1984a, 1984b, in Byram, 2000).

Since the last decade, some educators (e.g. Gaskins, 1994, in Newman, 1996) have begun to appreciate the pedagogical values of literature-based approaches to reading instruction and their findings are throwing light on the contributions of literary texts to reading comprehension. Grainger (2008) recently explored the interaction of drama and reading in learning. The author argues that "through the study of their interaction and an examination of the parallel processes at work, the potential of drama as a tool for learning about reading is more fully revealed"'(p. 29).

In the end, it should be remembered that "what we urgently need is to do more research on the mechanisms of learning and accompany new proposals and methods with more experimental evidence before we bring them into the classroom" (Sanchez, 2004, p. 65). 


\section{Conclusion}

This study has been carried out to find the effectiveness of reading short drama on the performance of advanced EFL learners in the development of vocabulary. The first step was to choose the participants of the study with the same language proficiency (advanced level) who were studying English as a foreign language. Participants who were advanced learners were selected from Zabansara Institute in Tehran. Before the beginning of the treatment, it was essential to make sure that the participants of the study were homogeneous in their proficiency level. For this purpose, the results of the homogeneity test (TOEFL Test) were used as a criterion for homogenizing the participants. The 40 participants were randomly assigned to two groups (each consisting of 20 students): one group for reading drama (the experimental group), and one group for traditional reading (traditional reading). A vocabulary test was used as a pretest to check the participant's vocabulary proficiency. During the treatment period, participants in the experimental group focused on reading short dramas while participants in the control group received reading instructions through traditional methods. After the treatment, the same vocabulary test was used as a post-test to see the changes. The data were entered into the SPSS software for analysis; the results clearly demonstrated the contribution of reading drama to the development of vocabulary skill of Iranian advanced EFL learners.

\section{References}

Brown, H. D. (2000). Principles of language learning and teaching $\left(4^{\text {th }}\right.$ ed.). Longman. New York: White Plains.

Brumfit, C. J. (1986). Reading skills and the study of literature in a foreign Llanguage. In Brumfit, C. J., \& Carter, R. A. (Eds) (1986), Literature and language teaching (pp. 184-190). Oxford: Oxford University Press.

Byram, M. (Ed) (2000). Routledge encyclopedia of language teaching and learning. London: Routledge: Taylor \& Francis Group.

Gajdusek, L. (1988). Toward Wider Use of Literature in ESL: Why and How. TESOL Quarterly, 22, 227-257. http://dx.doi.org/10.2307/3586935

Grainger, T. (2008). Drama and reading: Illuminating their interaction. [On-line]. English in education: The role of literature, 32, 29-37. Abstract from Wiley Interscience: Journals: English in Education.

Hatch, E., \& Lazaraton, A. (1995). The research manual: Design and statistics for applied linguistics. Boston: Heinle \& Heinle Publishers.

Heath, S. B. (1993). Inner City Life Through Drama: Imagining the Language. TESOL Quarterly, 27, 177-192. http://dx.doi.org/10.2307/3587142

Kelsall, M. (1985). Studying drama: An introduction. Edward Arnold. A division of Hodder \& Stoughton.

McKay, S. L. (1986). Literature in the ESL classroom. In Brumfit, C. J., \& Carter, R. A. (eds) 
(1986), Literature and language teaching (pp. 191-198). Oxford University Press.

McKay, S. L. (2001). Literature as content for ESL/EFL. In Celce-Murcia, M. 2001. Teaching English as a second or foreign language ( $3^{\text {rd }}$ ed) (pp. 319-332). Boston, MA: Heinle \& Heinle.

Moradan, A. (2006). The miraculous power of poetry as a language teaching device in EFL classes. TELL, 1, 103-121.

Newman, M. (1996). Towards an ESOL literature. TESL-EJ. Teaching English as a Second or Foreign Language, 2, 1.

Obeidat, M. M. (1997). Language vs. literature in English departments in the Arab world. Forum, 35(1), 30.

Oster, J. (1989). Seeing with Different Eyes: Another View of Literature in the ESL Class. TESOL Quarterly, 23, 85-103. http://dx.doi.org/10.2307/3587509

Robinson, H. (2002). Using drama texts in classroom. [Online] Available: http://www.teachingenglish.org.uk\THINK \literatureldrama_texts.shtml.html (April 8, 2010)

Sanchez, A. (2004). The task-based approach in language teaching. IJES. International Journal of language Studies, 4, 39-71.

Stern, S. L. (1991). An integrated approach to literature in ESL/EFL. In Celce-Murcia, M. (1991), Teaching English as a second or foreign language (2nd ed.) (pp. 328-345). Boston, MA: Heinle \& Heinle.

Ur, P. (1996). A course in language teaching: Practice and theory. Cambridge: Cambridge University Press.

\section{Copyright Disclaimer}

Copyright reserved by the author(s).

This article is an open-access article distributed under the terms and conditions of the Creative Commons Attribution license (http://creativecommons.org/licenses/by/3.0/). 